\title{
Awareness of Pregnant Women Regarding Pregnancy and Safe Delivery in Selected Rural Area
}

\section{S. M. Azmol Hossain' Md Monoarul Haque ${ }^{2 *}$ Md Rijwan Bhuiyan ${ }^{3}$ Nantu Bikash Tripura ${ }^{4}$ Jakir Hossain Bhuiyan ${ }^{5}$ Itrat Aziz}

${ }^{1}$ Department of Public Health, ASA University of Bangladesh Dhaka, Bangladesh.

${ }^{2}$ Department of Community Nutrition Faculty of Public Health Bangladesh University of Health Sciences (BUHS) Dhaka, Bangladesh.

${ }^{3}$ Department of Health Education \& Health Promotion Bangladesh University of Health Sciences (BUHS) Dhaka, Bangladesh.

${ }^{4}$ Medical Officer

Bangladesh Institute of Health Sciences (BIHS) Dhaka, Bangladesh.

${ }^{5}$ Consultant, UNICEF

${ }^{6}$ Department of Gynae \& Obstetrics Bangabandhu Sheikh Mujib Medical University (BSMMU) Dhaka, Bangladesh.
*Correspondence to:

\section{Md Monoarul Haque}

Fellow

Department of Community Nutrition

Faculty of Public Health

Bangladesh University of Health Sciences (BUHS)

125/1, Darus Salam, Mirpur, Dhaka-1216, Bangladesh

Cell: +8801915839550

e-mail: monoarmunna@yahoo.com

\begin{abstract}
Objective: This cross sectional descriptive study was conducted to explore awareness level of pregnant women regarding pregnancy and safe delivery in selected rural area. Methodology: This community based cross sectional descriptive study was carried out at Ullapara Upazila, Sirajgonj District among 120 pregnant women in a rural community. Non probability sampling technique and pretested semistructured questionnaire was used to collect data. Results: Majority of the respondents $(65 \%)$ were between 20-34 years of age group. Most of the respondents were housewives $(85 \%)$. Majority $(65 \%)$ of the respondents received antenatal care, and among them only $5 \%$ respondents received complete antenatal care and $25 \%$ received postnatal care. Majority $(75 \%)$ of the respondents had not received postnatal care (PNC). Majority $(85 \%)$ of the respondent planning their delivery in the home and $15 \%$ respondent planning their delivery in the delivery center. About $50 \%$ of the respondents got information regarding pregnancy and delivery care through health workers. Besides $35 \%$ of respondents got information through doctor. Moreover 50\% participants knew about the obligatory indications and 50\% did not. Sixty percent participants did not know follow-up regarding PNC. Only 25\% received PNC. Besides $60 \%$ participants did not know about warning sign during delivery while $40 \%$ faced complications during their last delivery. About 55\% participants did not have knowledge regarding baby care. Moreover 55\% participants did not take contraceptive method after their delivery. Conclusion \& Recommendation: Attention should be given to improve education level and employment status of the people, as well as supply of all of the necessary equipment and EOC should also be incorporated. Regular awareness program may have to be conducted; Government and non-government organizations should be integrated more in pregnancy issue and post-delivery care. Development and strengthen behavioral change of communications and activities in order to create awareness about pregnant women are also important indeed.
\end{abstract}

Key words: Awareness programme; pregnant women; post delivery care.

\section{INTRODUCTION}

Childbirth is a very important event in women's life. But complications during pregnancy and childbirth are a leading cause of death and disability among women of reproductive age in developing countries ${ }^{1}$. Every day, approximately 800 women die from preventable causes related to pregnancy and childbirth and $99 \%$ of all maternal deaths occur in developing countries. Where maternal mortality is higher in women living in rural areas and among poorer communities ${ }^{2}$. Maternal mortality is a serious public health concern in Bangladesh. According to a study released in 2010, Bangladesh was one of eleven countries that, when combined, were responsible for approximately $65 \%$ of maternal deaths around the world ${ }^{3}$. Bangladesh has reduced maternal mortality by $40 \%$ over the last nine years ${ }^{4}$. It is estimated that in Bangladesh maternal mortality ratio is at 194 per 100,000 live births dropping from 322 per 100,000 in 2001. 
Bangladesh needs to further reduce maternal mortality by $25 \%$ in order to meet the $2015 \mathrm{MDG}^{5}$. The main causes of maternal mortality in Bangladesh are Bleeding and post-partum hemorrhage (29\%), Eclampsia (24\%), Obstructed labor (10\%), Abortion $(5 \%)^{6,7}$. It is important that, to reduce MMR there must be ensure the following things: increased use of skilled care at birth, improved safer abortion practices, changes in causes of maternal mortality to those less amenable to management, societal changes (socioeconomic development, education of women, empowerment of women), improved birth-spacing, changes in fertility through the shift of riskgroups (high parity to lower parity; older age to younger age), Improved maternal nutritional status (role of improved maternal nutrition, e.g. body mass index and anaemia) ${ }^{8}$. The government of Bangladesh has been pursuing the strategy through establishment of family welfare centres (FWCs), maternal and child health $(\mathrm{MCH})$ units and Maternal \& Child Welfare Centres (MCWCs) in the context of a primary health care (PHC) in Bangladesh to reduce maternal mortality. Bangladesh Govt. provided antenatal services to the potential clients in the community through this project but the coverage of population with antenatal care is not satisfactory. 'There are several factors responsible for the under utilization of these facilities. The perceptions of health and health care by the beneficiaries i.e. the mothers, families and community leaders are factors that may influence the utilization of services. In this study, therefore, the researcher has tried to find out the women's perception of problem during pregnancy and delivery, and utilization : antenatal care facilities in a rural community of Bangladesh.The proper utilization of antenatal care of pregnant mothers is believed to greatly reduce neonatal mortality and maternal mortality in our country, particularly in rural communities.

By this study we can know the level of awareness among the pregnant women about antenatal, Intranatal and postnatal care practice. Primary aim of this study is to achieve at the end of a pregnancy a healthy mother and a healthy baby. Researchers, who are working and will conduct researches in relevant topics, may find this study helpful in correlating their findings. I hope this study finding could bring a change in future in poor and developing countries include Bangladesh.

\section{METHODS}

This study was community based cross- sectional study conducted in Selected rural community in Ullapara Upazila, Sirajgonj District, Bangladesh. The study period was from January 2013 and end in June 2013 (Six months). This study was carried out amog pregnant women in selected rural community in Ullapara Upazila. To conduct this study 120 individuals were selected purposively. In this study semi structured questionnaire was used as a tools containing sociodemographic information, pregnancy related information, ANC care, PNC and knowledge about baby care. Face to face interview methods was used to collect data and was analyzed using SPSS version 17. All ethical issues were considered during conducting this study and respondents were informed about inform consents and confidentiality of their infomations.

\section{RESULTS}

Socio-demographic characteristics of the respondents Table 1 shows that out of total 120 respondents, $30 \%$ in the age group of 25-29 years, followed by 20\% in 30-34 years of age group. Only $18(15 \%)$ each were in the age group of $15-19$ 1nd 20-24. Of the total 76 respondents, $63 \%$ had monthly family income of below taka 10,$000 ; 17 \%$ had monthly family income between taka 10,001-20,000, and only 6 had monthly family income above Taka 30,000.

The educational qualifications of the 120 respondents have been shown in this table. $48 \%$ of the respondents had primary level of education, $20 \%$ had secondary level and $10 \%$ had higher secondary level. Majority of the respondents were housewives $(85 \%)$, and only $6 \%$ were government service holder and $6 \%$ were private service holder. Bulks of the respondent's husband are day labor (27\%), and only $24 \%$ were private service holder and $3 \%$ were business.

Table 1: Socio demographic characteristics of the respondents

$\begin{array}{llrr} & \text { Items } & \text { Frequency } & \text { Perce } \\ \text { Age group } & & & \\ & 15-19 & 18 & 15 \\ 20-24 & 18 & 15 \\ 25-29 & 36 & 30 \\ & 30-34 & 24 & 20 \\ & 35-39 & 19 & 16 \\ & 40+ & 5 & 100 \\ & \text { Total } & 120 & 63 \\ \text { Monthly income } & & 76 & 17 \\ & <10000 & 20 & 10 \\ & 10001-20000 & 6 & 18 \\ & 20001-30000 & 18 & \end{array}$

Educational level

Class I-V $48 \quad 40$

Class VI-IX $24 \quad 20$

$\begin{array}{lll}\text { SSC } & 18 & 15\end{array}$

HSC $12 \quad 10$

Graduate $\quad 12 \quad 10$

$\begin{array}{lll}\text { Total } & 120 & 100\end{array}$

Occupation

House wife $\quad 102 \quad 85$

Govt. Service $6 \quad 5$

Pvt. Service 6

Others 6

$\begin{array}{lll}\text { Total } & 120 & 100\end{array}$

Occupation of Husband

Day Labor $\quad 32 \quad 27$

Rickshaw Puller $14 \quad 12$

$\begin{array}{lll}\text { Farmer } & 23 & 19\end{array}$

Govt. Service $18 \quad 15$

Private Service $29 \quad 24$

Business 4

Total $\quad 120$

100 
Awareness about pregnancy and safe delivery of the respondents

A volume of the respondents had taken interval for 3 years of their pregnancies, $(50 \%)$, and only $30 \%$ had taken interval for 2 years of their pregnancies. A bulk of the respondents (42 participants, 35\%) had no ANC visit, 20\% respondents (24 participants) had 3 ANC visits, 5\% had 5 ANC visits (6 participants). Majority of the respondents (102 participants, $85 \%$ ) had taken TT in their pregnancy period, $10 \%$ had not taken TT in their pregnancy period (12 participants).

78 respondents $(65 \%)$ have taken food supplement during pregnancy, while $42(35 \%)$ have not taken food supplement during pregnancy. Maximum $(85 \%)$ of the respondents had home delivery and $15 \%$ of the respondents had institutional delivery. 55\% participant had faced no complication during last delivery (66 participants) and $45 \%$ participants had face complication during last delivery (54 participants).

$55 \%$ participant had no knowledge about baby care (66 participants) and $45 \%$ participants had knowledge about baby care (54 participants). $75 \%$ participants had not received of PNC (90 participants) and 25\% participants had received of PNC (30 participants). $60 \%$ participants had no follow up PNC (72 participants) and $40 \%$ participants had follow up PNC (48 participants).

Table 2: Awareness about pregnancy and safe delivery of the respondents.

Items Frequency Percentage

\section{Birth spacing}

$\begin{array}{rr}2 & \\ 3 & \\ 4 & \\ 5 & \\ 6 & \\ \text { Total } & 1\end{array}$

36

60

12

6

6
120

120

$1 \quad 18$

$2-18$

$\begin{array}{ll}2 & 24 \\ 4 & 12\end{array}$

4

5

6
Total

TT taken

Total

NO

Total

Food supplement taken

Yes $\quad 78$

No

Total

Place of delivery

Home

Hospital

Total

Face any complication

during last delivery

Yes

No

Total

Knowledge in baby care

Yes

No

Total

PNC

Follow up in PNC

Yes

No
Total

\section{Yes}

No

Total
30

50

10

5
100

15

15

20

10

35

100

85

15

100

65

35

100

85

15

100

45

55

100

45

55

100

25

75

100

40

60

100

\section{DISCUSSION}

The age distribution of this study shows that majority of the respondents age group belongs to 25 to 29 which is the golden time of pregnancy ${ }^{9}$. Among them near about half (48\%) of the respondents have primary education which indicate increasing female literacy rate in Bangladesh from last two decades ${ }^{10}$. Majority of the respondents (85\%) were housewife.

Study shows that about half (50\%) of the respondents take 3 years interval for next pregnancy. Where A study in USA, Infants conceived 18 to 23 months after a previous live birth had the lowest risks of adverse peri-natal outcomes; shorter and longer inter-pregnancy intervals were associated with higher risks ${ }^{11}$. About 35\% respondents have taken 6 times ANC and no respondents had found who did not take ANC care during their pregnancy. Where at least one ANC care should be needed during pregnancy ${ }^{12,13}$. Study also found majority of the respondents $(85 \%)$ have taken TT injection, more than half (65\%) respondents have taken nutritional supplements during their pregnancy. Which indicate the improvement of primary health care delivery system in Bangladesh [8]. But almost two third of the respondents ( $85 \%$ ) did their delivery at home where only a few (15\%) did in any institution which shows the current situation of bangladesh where about $90 \%$ delivery done at home ${ }^{13}$. Study found still now more than one third (45\%) respondents faced some complication during their delivery. About half (55\%) of them have knowledge about baby care. $75 \%$ have taken PNC are properly which actually represent the similar findings of some previous studies ${ }^{8,13}$. Basically to meet the MDG-5 govt. of Bangladesh has taken some initiatives which reduce about 194 per 100,000 live births dropping from 322 per 100,000 in 2001 and Bangladesh needs to further reduce maternal mortality by $25 \%$ in order to meet the 2015 $\mathrm{MDG}^{5}$.

\section{CONCLUSION}

From this study we have found that there is a significant improvement of pregnancy and baby care in Bangladesh. But till now we need to concentrate in some area like ensuring institutional delivery system, improving maternal nutrition. Although this study does not represent the whole country so need to further study.

\section{DISCLOSURE}

All the authors declared no competing interest. 


\section{REFERENCES}

1. Health statistics and information systems, WHO [Internet] 2010 Nov 1 [updated 2011 Jan 1; cited 2013 Apr 8]. Available from: http://www.who.int/healthinfo/statistics/indmaternalmortality/en/.

2. WHO, Maternal mortality [Internet] 2012 May 10 [updated 2013 Jan 1; cited 2013 Apr 15]. Available from: http://www.who.int/mediacentre/factsheets/fs348/en/.

3. World Health Organization, et al. Trends in Maternal Mortality 1990-2008. http://www.who.int/reproductivehealth/publications/monitoring/9789241500265/en/index.html.

4. BRAC. Dramatic Fall in Maternal Mortality in Bangladesh. Feb 13 2011. http://www.brac.net/node/832.

5. Hasib NI. Maternal Deaths Drop Sharply. Bdnews24. Feb 132011. http://bdnews24.com/details.php?id=187182\&cid=13.

6. The Department of Family and Community Health. Bangladesh and Family Planning: An Overview. World Health Organization, Regional Office for South-East Asia.

7. Bangladesh Maternal Health Service and Maternal Mortality Survey (BMMS) 2001. National Institute of Population Research and Training, ORC Macro, Johns Hopkins University, Dhaka, December 2003.

8. Chowdhury M.E, Ahmed A, Kalim N, and Koblinsky M. respecCauses of Maternal Mortalitb Decline in Matlab, Bangladesh. J Health population Nutrition [ Internet]. 2009 [cited 2010 Apr 22];27(2):108-123.

9. CDC, 2010, National health report, [Internet], [cited 2013 April 10]. Available from: http://www.cdc.gov/nchs/data/nhsr/nhsr051.pdf.

10. World bank, 2012, Available from: http://data.worldbank.org/country/bangladesh.

11. N Engl J Med. 1999 Feb 25;340(8):589-94. Effect of the interval between pregnancies on perinatal outcomes. Available from: http://www.ncbi.nlm.nih.gov/pubmed/10029642.

12. Lincetto O, 2012, WHO report on Antenatal Care, Available from: http://www.who.int/pmnch/media/publications/aonsectionIII_2.pdf.

13. UNICEF, 2001, Maternal Health in Bangladesh, Available from: http://www.unicef.org/bangladesh/MATERNAL_HEALTH.pdf. 